\title{
Dance Forms of the Statues in Yungang Grottoes
}

\author{
Zhao Meng ${ }^{1, *}$, Li Jia ${ }^{2}$ \\ ${ }^{1}$ School of Music, Shanxi University, Shanxi, China; Krirk University, Bangkok, Thailand \\ ${ }^{2}$ College of Music, Shanxi Normal University, Shanxi, China \\ *Corresponding author
}

Keywords: Yungang Grottoes, Dance Forms, Dance in Shanxi

\begin{abstract}
Yungang Grottoes are a famous cluster of grottoes in China with a long history and rich cultural accumulation behind. The dance forms in the Yungang Grottoes represent the development characteristics of different historical periods. The study of them is of great significance and influence for our art development, history research, as well as the exchange and discussion of Chinese and Western cultures. Starting from the formation and development of the Yungang Grottoes, this paper briefly analyzes the influence of the formation of the Grottoes and the integration of multiple cultures. On this basis, this paper studies the grotto dance forms formed in this background. Through this research, the author hopes to make a contribution to the study of the dance forms of the statues in grottoes in Shanxi, and to contribute to the development of dance in Shanxi in the future.
\end{abstract}

\section{Introduction}

Grotto art was introduced into China with Buddhism in the 5th to 4th centuries BC. It arose in the Wei and Jin dynasties and flourished in the Sui and Tang dynasties, and occupied a very important position in ancient Chinese culture. The main existing grottoes in China include the Dunhuang Grottoes in Gansu, the Yungang Grottoes in Datong, Shanxi, and the Longmen Grottoes in Luoyang, Henan. Although they are referred to as Buddhist grottoes, after they were introduced into China and merged with the local culture, they have evolved from pure Buddhist art to an important carrier of politics, economy, culture, architecture, fine arts, music, dance, and secular life in the development of Chinese history. Among them, the Yungang Grottoes are well-known both at home and abroad for their perfect integration of traditional Chinese carving art with Indian Gandhara art and Dodder style, and for being the first to "sinicize" grotto art. The Yungang Grottoes are located in Datong City, Shanxi Province. They are about one kilometer long from east to west, containing 45 main caves and more than 51,000 stone statues. They are one of the largest cluster of grottoes in China, and are of great significance both in appreciation and academic research.

\section{The formation, development and artistic attainments of Yungang Grottoes}

It took more than 60 years from the beginning of the excavation to completion of the Yungang Grottoes from the early years of Heping of Emperor Wencheng to the fifth year of Zhengguang of Emperor Xiaoming. According to the grotto shapes, the content of the statues, the images and the 
styles of carving, the development of the grottoes can be divided into the following stages.

\subsection{Five grottoes of Tanyao, the symbol of the emperor}

The early grottoes, now known as caves 16-20, can also be referred to as the Five Crottoes of Tanyao, symbolizing the emperor. From a plan view, they are in the shape of a horseshoe, with a raised dome and a thousand Buddha statues on the outer wall. As the main statue, the image of the Buddha of Three Periods is tall and majestic, with a full face, a high nose, inward eyes, and shoulders erected, creating a strong, solid and simple feeling. The sculpture technique of this grotto was inherited from the Han Dynasty, and merged and absorbed the artistic style of ancient India, forming a unique sculpture art.

\subsection{The magnificent Taihe style}

with the scene of them sitting side by side, and also different Dharma stories. The overall image and various decorations of Buddha statues also emerged endlessly, and a large number of new themes and the combination of sculpture art appeared in this period. In the middle of the grottoes, many Chinese elements were integrated in the creation process, showing a clear The mid-term grottoes were the heyday of Yungang Grottoes, not only including numerous grottoes, but also had talents from all walks of life who moved to Luoyang from the Northern Wei Dynasty. The most stable period for them to build and develop together was completed before Emperor Xiaowen moved the capital, lasting for over 40 years. Different from the appearance of the early grottoes, the planes of the middle grottoes are mostly square or rectangular. Some grottoes have pylons, and some have front or back chambers. The overall wall layout presents upper and lower layers and left and right sections. The subject content of the statues also became varied and more colorful. They emphasized Sakyamuni and Maitreya Buddha, trend of Sinicization, making it an important period of the Sinicization of Buddhist grotto art. The rich content, exquisite carvings and other features of artistic style are very different from the early grotto sculptures. During this period, there were higher requirements for statues and carvings, and the overall style tended to be Sinicized.

\subsection{Fresh and elegant thin images}

After the Northern Wei Dynasty moved the capital, the excavation of the Yungang Grottoes was suspended in large numbers. However, during this period, there was a trend of opening up small and medium-sized grottoes among the middle and lower classes. Such small grottoes were dug one after another until the fifth year of Zhengguang during the reign of Emperor Xiaoming. Medium and small grottoes with different sizes covered the cliffs. Although they are not as magnificent as large grottoes, they have formed another artistic style. Most of these grottoes appeared independently, and no longer appeared in groups. Their subject matters were similar to those of the mid-term grottoes. There are many depictions of Sakyamuni or Maitreya in the upper part and and Sakyamuni in the lower part. Most of these Buddha statues have thin faces, slightly long necks, and slightly narrow shoulders. This image was to match the Sinicization style promoted in the late Northern Wei Dynasty, and was intended to portray more elegant and graceful images. Later, this image became a rather typical feature of Buddhist statues in the late Northern Wei Dynasty. This style is not only reflected in the Yungang Grottoes, but can also be seen in other grottoes in China, having a great influence on Chinese grotto art. 


\section{The dance forms and characteristics of Yungang Grottoes}

Dance images in grottoes are different from ordinary paintings. Their content and style are not only related to the Buddhist sects in various places, but are also greatly related the dance styles, music styles and aesthetics in these places. As one of the famous grottoes in China and a masterpiece from Shanxi, the Yungang Grottoes have become a treasure in the history of China with their magnificent momentum and the fusion of Chinese and Western statues. The Yungang Grottoes are a prominent result of cultural exchanges between the East and the West, as well as a great work blending the Eastern and the Western cultires. It was the unique excavation spirit of the ancients that contributed to today's grotto dances with different styles and varying aesthetic characteristics.

\subsection{The brave and vigorous vajra warrior possessing both strength and beauty}

The carved stone warriors in Grotto 16 of the Yungang Grottoes squat side by side neatly and uniformly. They raised the niche with their hands, the streamers drooped, and their faces were joyful, like a group dance in the same rhythm as the breathing, perfectly highlighting strength and beauty. The image of warriors came from one of the guardian gods of the "Eight Divisions of Dragons and Devas". They appear at the bottom of the grotto murals. They are the guardians of the grotto, as well as the guards and attendants of the Buddhas and Bodhisattvas. Most of their images are vigorous and majestic, dancing with hands, holding weapons or huge stones in their hands to support the grotto, and some are holding up the Buddha seat or standing on both sides of the Buddhist niche to guard. Their facial expressions were serious and sharp, their eyes protruding and glaring. In terms of physique, they not only show fitness and give people a sense of strength, but also reflect the beauty of dance, looking rough but with a unique flavor.

\subsection{Beautiful and elegant flying dancers with diverse styles}

It is stipulated in the Buddhist scriptures to make offerings to the Buddha through music and dance. Therefore, the images of flying apsaras and dancers are often seen in the Yungang Grottoes. Most of the flying apsaras in the Yungang Grottoes are relief sculptures with exquisite carvings. For example, grotto 6 "Buddha's Grotto" is the most concentrated grotto of apsaras, looking quite active because there are apsaras everywhere in the grotto. In grotto 7 the "Beauty Grotto", flying ribbons flutter up with a smile on the apsaras' faces, while musicians hold musical instruments and play in the air.

The images of apsaras are Gandharva and Kinnaras of the Indian Brahmanism. They are the guardian gods of the "Eight Division of Dragons and Devas". They are good at singing and dancing, and specialize in scatter flowers and playing music for the Buddha. In the Yungang Grottoes, the early apsaras were strong and fit, topless, with the beauty of nomads. While the apsaras in the later period, had delicate faces and slim figures, highlighting the features of Sinicization. This reflects that after Emperor Xiaowen of the Northern Wei Dynasty implemented the Sinicization policy, in the subsequent excavation of grottoes, the design of apsaras' dancing poses not only had the vigor and heartiness of the northern peoples, but were also with the elements of gentle and elegant Han costumes.

In general, among the music-playing apsaras in the Yungang Grottoes, some put the palms together, some are scattering flower or applying incense, looking graceful and creating a fairy ambient in the air. 


\subsection{A skillful use of all kinds of music instruments and props}

"Hundreds and thousands of heavenly instruments produce music without being played" means the joy in the heaven and the praise of Buddhas. According to statistics, the 22 existing grottoes in Yungang Grottoes contain the image of carved musical instruments, with more than 500 sculptures of various musical instruments belonging to 28 categories, and over 60 music bands. Musical instruments include flute, bamboo flute, panpipe, xun, sheng, pipa, vertical bamboo flute, waist drum, tambourine, etc. Among the grottoes, Grotto 12 is referred to as the "Grotto of Music", looking as if a feast of music is being held inside. All kinds of performers hold different instruments, some putting their palms together, twisting the waist and the hip, some taking the legs back, waving the arms and having the head leaning. Their dancing postures are coherent and their facial expressions are lifelike. These dancers are with Han, Xiliang, Qiuci, and Tianzhu musical instruments, some have high hair buns (Central Plains dancers), and some have reverse hair (minority dancers). They appeared together, fully demonstrating the unique music and dance structure combining the music and dance of the Central Plains in Shanxi with the music and dance of the northwest nomads.

\subsection{An all-embracing combination of the Central Plains and the Western Regions}

Due to the historical background, the statues in Yungang Grottoes show a unique aesthetic in terms of shape and clothing. For example, the giant Buddha statue of Yungang has big ears and big eyes, highlighting the characteristics of the Xianbei people. The Xianbei hat of the Yungang Grottoes statues has a round element in a square frame, and there are "drape cloths" hanging down to the shoulders on both sides and the back of the head. This is a common hat worn by the Xianbei people in their daily lives. In addition, because the Xianbei people are a grassland nation, in order to adapt to the life of horse riding, their clothing is mostly with leather boots and waistbands. These costume features are more or less reflected in the stone sculptures. For example, the supporting warriors, and apsaras on the south wall of Grotto 5 of the Yungang Grottoes all wear short clothes, jackets having buttons down the front and waistbands. The dance image in Yungang Grottoes is also reflected in the combination of Central Plains dance, Xiliang dance, Western Region dance, Korean dance, and the dance of the Xianbei nationality. For example, in Grotto 20, on the right side of the head of a big Buddha, flame patterns and an apsara are seen, with long hair and pigtails, and a delicate and beautiful face that echoes the lively and vivid image of a young girl from Xinjiang; the dancing posture of "filliping" is a typical movement of Qiuci dance; the dancing posture of "jumping on the threshold" in Grotto 12 is very similar to the dance movements in opera; the hanging drum on the chest of the heavenly dance is a typical image of the folk dance of the Han nationality in the Central Plains... Countless examples are showing that Yungang Grottoes are a masterpiece integrating the cultures of the Western Regions, nomads and the Central Plains, and are a treasure trove of dance materials.

\section{The significance of studying the dance in the statues of Yungang Grottoes}

The cultural charm and aesthetic connotation of dance in Yungang Grottoes have been separated from the pure dance category. They have spread from ancient times to the present, and have had a positive impact on the development of art and cultural dissemination today. Through the collection and sorting of predecessors' research materials on Yungang Grottoes and music and dance culture, this research can fill in the data gap of Yungang dance from the perspective of dance; by in-depth summary of the morphological characteristics and artistic value of Yungang music and dance, we can explore the evolution of Yungang dance for the regionalization and nationalization of Buddhist 
dance combining Buddhism and local folk culture; through a comparative study with Dunhuang dances that have already had a certain system and influence, we can further derive the research importance and aesthetic value of Yungang dance, as well as its development direction; through the discussion on the inheritance and development of Yungang Dance, we can find specific methods and ideas for the protection and innovation of Yungang Dance, so as to promote the reproduction and creation of Yungang Dance, carry forward the mural dance with national characteristics and enrich the content of Chinese dance types. The Yungang Grottoes is a key cultural protection object in China, and it is also an important basis for scholars to conduct cultural studies. It is of great significance whether it is the study of history, the exchange of Chinese and Western cultures, or the development of subsequent dances. As later generations, while studying, we must also pay attention to the protection and repair of historical relics. We should not change the appearance of history, but should also maximize the development of commendable places in history and leave a valuable history for future generations.

The sculptures in Yungang Grottoes are not lifeless historical symbols, but living artistic images. They record the thousand-year development of Chinese civilization, including the integration of Chinese and foreign cultures, and call for the inheritance through generations. The restoration and development of dance in Yungang Grottoes is not only to inherit cultural symbols, but to reproduce the lost civilization. More importantly, it is a carrier for inheriting and carrying forward the excellent traditional national culture, and an important cornerstone for building cultural self-esteem, national self-esteem, reshaping cultural self-confidence, and enhancing national self-confidence. It will play an irreplaceable positive role in promoting the construction of modern cultural ecology, rejuvenating cultural dreams, and realizing the Chinese dream.

\section{References}

[1] Liu Xiaona; A Study on the Expression of Dancing Images in Yungang Grottoes[D]; Hebei University;(2019)

[2] Luo Ling. How to capture dancing images[J]; Beauty and Times (2); Issue 04, (2015)

[3] Xu Qian. Famous Grottoes in China [M] Jilin: Jilin Culture and History Publishing House,(2014)

[4] Gao Chao. On the Naked Dancing Images in Buddhist Grottoes and Temples [D] Minzu University of China, (2013)

[5] Guan Xin. Buddhist Architecture and Sculptures in India. Fa Yin, Issue 4, (1988)

[6] Su Bai. Gather of Pingcheng Strength and the Formation and Development of the "Yungang Model", Grottoes in China: Yungang Grottoes (I), Cultural Relics Publishing House, (1991).

[7] Li Zhiguo, Liu Jianjun. An Investigation of the Grottoes of Luyeyuan in Pingcheng in the Northern Wei Dynasty, Grottoes in China: Yungang Grottoes (I), Cultural Relics Publishing House, (1991).

[8] Institute of Archaeology, Chinese Academy of Social Sciences. Yongning Temple in Luoyang in the Northern Wei Dynasty (a Report of Archaeological Excavation from 1979 to 1994), China Encyclopedia Publishing House, (1996) 